\title{
Battling Promethean dreams and Trojan horses: Revealing the critical discourses of geoengineering
}

\author{
Jonas Anshelm and Anders Hansson
}

\section{Linköping University Post Print}

\section{Tweet}

N.B.: When citing this work, cite the original article.

Original Publication:

Jonas Anshelm and Anders Hansson, Battling Promethean dreams and Trojan horses: Revealing the critical discourses of geoengineering, 2014, Energy Research \& Social Science, (2), 135-144.

http://dx.doi.org/10.1016/j.erss.2014.04.001

Copyright: 2014 Elsevier Ltd.

http://www.sciencedirect.com/

Postprint available at: Linköping University Electronic Press

http://urn.kb.se/resolve?urn=urn:nbn:se:liu:diva-108317 


\section{Introduction}

Geoengineering is a set of heterogeneous technologies that could counteract climate change by either altering the earth's global energy balance by reflecting sunlight or removing $\mathrm{CO}_{2}$ from the atmosphere. The options that attract the most attention are the injection of sulphur aerosols into the stratosphere, cloud seeding/whitening, air $\mathrm{CO}_{2}$ capture, and ocean fertilization, but more spectacular options such as space mirrors are also considered geoengineering [1]. Due to the potentially severe environmental risks accompanying several of these technologies, major uncertainties, and the fact that most of these options are unproven, geoengineering was long deemed undesirable or marginal in both international climate negotiations and scientific research [2]. It was not until Nobel laureate Paul Crutzen's [3] cautious encouragement of research into geoengineering, in a 2006 special issue in Climatic Change, that a more lively and open public debate on geoengineering emerged.

In the wake of this special issue, positive aspects of geoengineering dominated the debate, although serious concerns were raised [4,5]. In autumn 2013, geoengineering entered the agenda of the IPCC meetings, and geoengineering options will be considered by all three working groups contributing to the forthcoming Fifth Assessment Report in 2014. Its most vocal advocates even urge that these options must be treated as viable options, beside conventional mitigation methods, in international climate negotiations [6]. This marks a radical shift from the IPCC's 2007 statement, made despite the absence of cost calculations and risk assessments, that geoengineering options "remain largely speculative and unproven, and with the risk of unknown side-effects. Reliable cost estimates for these options have not been published." [7, p. 15]. Today the concern that climate change may be irreversible without geoengineering has become more common even in the climate science community than it was only few years ago [8].

As large-scale geoengineering ultimately entails exerting far-reaching control of the global climate system by applying technology, it evokes various ethical, emotional, and political challenges that are increasingly reflected in the public debate. Recurring arguments for geoengineering research are that the severity of climate change justifies new means to counteract global warming and that political failure means that conventional methods will be insufficient [4]. Sovacool [9], and Stirling [10] explain that a discourse analysis is a fruitful approach for social scientific scholars interested in for example climate change and energy issues because it can deepen the understanding of how objects, concepts and practices mutually constitute each other and are given meaning. In line with this understanding geoengineering is a narrative, based on a system of ideas, beliefs and ideology, which is laden with contradictions that are constantly re-produced and negotiated. By applying this perspective social science may independently contribute to a wider plurality of social interpretations and hence influence framing priorities and questions for further research, and possibly also laying a ground for critique of prescriptive policy recommendations [cf 10].

Portions of the mass media debate on geoengineering have been examined in previous research, though the focus has not been on the critical discourse [4,11]. Buck [12] and Scholte et al. [11] claim that the geoengineering debate in the 2006-2009 period predominantly conveyed arguments for more geoengineering research; it was not until 2011 that geoengineering controversies were reported more explicitly and frequently in the mass media, probably because minor field experiments had taken place.

Previous research into the mass media debate on geoengineering applied content analysis primarily to quantify or categorize various themes or characteristics in a rather narrow set of articles from US or UK newspapers. Frames, discourses, metaphors, and storylines are concepts that have been applied to systematize, describe, and explain this material $[11,12,13,14,15,16]$. The present paper advances this research by scrutinizing the global public debate, predominantly the previously ignored critical discourse, but is unlike previous research in applying qualitative text analysis. Despite our qualitative approach, we have amassed a larger sample of articles with a wider geographical scope than used previously. By contrasting the critical discourse with prior research, we have expanded the analysis and deepened the understanding of the geoengineering debate. 
In mass media research into geoengineering, Scholte et al. [11] and Nehrlich and Jaspal [14] have emphasized investigating whether or not the geoengineering debate is opening up, i.e., whether the coverage of geoengineering is becoming wider-ranging and more diverse over time, and have reached opposite conclusions. Although we support Scholte et al.'s [11] conclusion that the debate is opening up, we argue that this matter is not of primary importance. It is more important to address the question raised by Cairns [17], i.e., what broader implications and states can be discerned behind the political pluralities in the debate? The present paper identifies the central claims in the discourse critical of geoengineering, exploring what subjects are the most controversial, and what worldviews, values, and problematizations are shared by the advocacy and critical discourses on geoengineering.

\section{Theory: Discourse and storyline}

To organize statements about a particular object or part of the world, we apply the concept of discourse. We treat discourses as specific ways to speak of and represent the world [18; cf. 4], and the actors within a specific discourse as using a language based on common definitions, judgments, assumptions, and contentions when addressing a topic [19]. We use the discourse concept analytically to structure and order the examined texts: discourses are not inherent to the texts, waiting to be discovered, but are constructed by the researcher. Discourses are constructed in the research process to make it possible to speak about patterns in a heterogeneous and complex reality. Lovell et al. [20] claim that complex environments are suitable for the storyline approach, which is a middle-range concept in relation to discourse. This means a focus on the intra-discursive characteristics and somewhat simplified explanations, in the sense that a storyline does not contain all the uncertainties and diversity of the discourse. Nevertheless, storylines play a key role in filling the gap between the more abstract concept of discourse and concrete textual events, for example, statements in articles, according to Hajer [21] and Heitman et al. [19]. The discourse concept helps explain the criticism of geoengineering at a more abstract level, while the storyline concept focuses on specific aspects and is closer to the empirical material. Hajer [21] explains:

Story lines are devices through which actors (stakeholders) are positioned, and through which specific ideas of blame and responsibility, and of urgency and responsible behaviour, are attributed. Through story lines stakeholders can be positioned as victims of pollution, as problem-solvers, as perpetrators, as top scientists or as scaremongers. (pp. 64-65)

The storyline concept commonly works in tandem with the concept of discourse coalition [19,21]; however, we aim neither to map the actors nor study, in depth, the practices in which the discursive activities take place [20]. We do not intend to identify specific actors or to pinpoint the discourses with which they are aligned. Lovell et al. [20] claim that it is sometimes not even possible to identify distinct groups of actors within the discourse coalitions. In the present case, we assume that there are no strong links between the storylines and discourse coalitions. In the geoengineering discourse, a specific actor may make statements belonging to several storylines, and actors may also be ambivalent and change their views over time. We claim that geoengineering's novelty, the lack of formal political processes concerning its development, and the few relevant field experiments complicate the identification and construction of discourse coalitions: the practice is in the making and the boundaries of potential coalitions are also in the making.

We also admit that there are few "pure" critics, as even actors criticizing geoengineering may express some conditional support for its deployment. Though specific actors have occasionally been selected in our analysis to exemplify a specific discourse or storyline, we assert that they do not necessarily agree on the range of views expressed in that discourse. However, as mentioned, the analytical focus is on discourses and storylines, i.e., abstractions of the content of mass media articles and various actors' statements and not on groups of actors taking a stand on geoengineering (cf. [22]).

\section{Material and methods}

The analysis relates primarily to our previous research, conducted in spring 2013, examining approximately 1500 articles published between 2006 and summer 2013. We used the Retriever database (a Nordic version of LexisNexis), which covers more than 12,000 newspapers globally, and 
applied the search strings "climate engineering" and "geoengineering AND climate". We included all articles written in either English, German, Swedish, Danish, or Norwegian, simply because these are the languages in which we are fluent. A total of about 115 articles, approximately $8 \%$ of the total, were categorized as critical of geoengineering, considerably fewer than the articles advocating geoengineering. Like Scholte et al. [11], we do not consider articles mentioning or discussing both the pros and cons of geoengineering as necessarily "balanced"; instead, we make the categorization depending on the articles' main argument, recommendations, or conclusions. However, in some articles both the discourse advocating geoengineering and the discourse critical of geoengineering were represented.

To enable comparative analysis of the discourses advocating and/or critical of geoengineering, we use a method identical to that of our previous study [4]. The texts were chronologically ordered and read several times to identify the most important passages relevant to the discourse critical of geoengineering. The texts were then coded and categorized in an ongoing analytical process of recoding and re-categorization. Recurring metaphors, emblems, notions, assumptions, claims, and other central meaning formations were identified, marked, clustered, and step by step interpreted as forming four coherent and distinct storylines. These storylines were found to together constitute a discourse, giving meaning to a specific aspect of the world. Our interpretations of storylines and discursive patterns are continuously supported with references to specific texts [23]. It is important to note that the cited texts are just some illustrative examples, and not all that could have been cited given sufficient space.

The images conveyed in the pro-geoengineering mass media discourse examined here are arguably not fully consistent with how its advocates would treat geoengineering if they were the primary source. The discourse and storylines are, as explained above, constructed by the authors; in addition, however, the journalists and other actors taking part in the debate may tend to dramatize the controversy by polarizing differences or emphasizing aspects deemed sensational or newsworthy. However, we do not consider these observations problematic for our inquiry, since it is primarily the discourse as represented in the mass media and public debate that we are analysing, i.e., we do not claim to be scrutinizing the stakeholders' actual positions, arguments, and motives on their own merits. Our perspective is nevertheless important, since the mass media debate is influencing the public understanding and the ongoing development of geoengineering, regardless of how accurately it captures technological potentials and risks and the diversity of standpoints. According to Scholte et al. [11], the mass media constitute the main arena for highlighting policy-relevant issues, and previous research has demonstrated that the media coverage of climate change issues has influenced sciencepolitics interactions. In addition, the mass media influence the public understanding of and attitudes to issues, which in turn can also influence politicians.

In addition, the inconsistencies in the argumentation concerning geoengineering, both within and between the two discourses, may be partly explained by the possibility that the actors are sometimes discussing specific geoengineering technologies that may differ considerably from each other, although that is not always made explicit. However, we are primarily interested in geoengineering as a grand global project or an idea, which also seems to be the most common perspective conveyed in both discourses [cf. 4]. Only occasionally do the articles explicitly discuss specific geoengineering technologies, although one can discern that solar radiation management and, even more specifically, sulphur aerosol injection (SAI) attract the most attention. Although the empirical material occasionally enables a more disaggregated analysis of geoengineering, our analytical focus is on geoengineering as an overall idea and on the intentions for initiating this grand-scale project; therefore, the analysis, for example, is not applicable to delimited debates concerning pros and cons of specific technologies. In other words, the present analytical scope is coherent with the dominant definition of geoengineering, i.e., the intentional large-scale technological management of the planet's climate. We claim that the individual discourses constituting the geoengineering debate are distinguished primarily by different views of the relationship between nature and humanity, the feasibility and desirability of controlling the planet, and the possibilities for changing societal structures. Geoengineering advocacy is about aspirations to make a radical change concerning controlling and regulating the global atmosphere and 
climate, and not about accepting or rejecting a specific geoengineering technology's potential to contribute a little to the existing portfolio of options for managing climate change. We also conduct a comparative analysis of the differences between the two discourses, as presented in Anshelm and Hansson [4]. It is worth noting that, in the scientific literature, very few researchers unreservedly support or oppose geoengineering implementation. In a review of scientific articles' abstracts and recommendations, Linnér and Wibeck [24] found that the most frequent recommendation was that more experimentation or research was needed and that geoengineering should be considered, with care, in a precautionary way as an emergency option. In the present paper, and in our previous paper on the pro-geoengineering discourse [4], we treat this and similar positions as advocating geoengineering, well aware that some "advocates" would probably not consider themselves as such. Hence, we include storylines that Hamilton [25] would probably label as cautiously supportive in the discourse advocating geoengineering, leaving only deeply sceptical or opposed storylines to be included in the discourse critical of geoengineering. The critical discourse also sometimes describes recommendations for more research as actually advocating geoengineering, often referring to the slippery slope argument. The core of the argument is that even a few small initial research steps will incrementally lead to grand-scale implementation. This discussion is expanded on in the section "The geoclique and the Trojan horse".

\section{Results: The discourse critical of geoengineering}

In 2009, a discourse critical of geoengineering began emerging, mainly in American magazines featuring critical social and environmental debate and in German newspapers. Four distinct storylines can be discerned in this discourse. The first storyline describes the devastating environmental risks of geoengineering. The second explains why geoengineering, despite its alarming shortcomings, has been widely recognized as an option for counteracting climate change. The third depicts the actors promoting the technologies and their motives, while the fourth addresses the democratic deficit concerning these technologies and why the public must be included in the geoengineering debate.

\subsection{The technological gamble with the planet}

The first storyline emphasizes that that these new technologies could lead to ozone depletion, ocean acidification, biodiversity degradation, regional droughts, extreme weather, and even increased global warming. The extent of the side-effects is held to be unforeseeable and the risks beyond imagining because of these schemes' large temporal and spatial scales [,26,27,28,29,30,31,32,33,34,35,36]. Geoengineering schemes are accordingly treated as more dangerous than any previous technological enterprise, and are understood as expressing megalomania [34,36,37,38,39]. The metaphor of an unacceptable gamble is recurrent. Geoengineering is characterized as, for example, "a dangerous game with unclear rules", "the biggest technological gamble of all", "rolling the dice", "gaming with the earth", and even as "completely nutty" [31,34,35,38,40,41]. To emphasize this view, ancient myths are invoked. Conducting geoengineering research or deploying the technology is likened to opening Pandora's box or described as a modern Promethean dream [22,42,43,44,45,46,47,48]. Prometheus, who stole fire from the gods to elevate humanity to a divine level and was punished for his hubris, is cited to discredit the efforts of geoengineering scientists, and to insist that these new technologies are something that humanity should relinquish.

Besides the dangerous aspects, other reasons for opposing geoengineering are repeatedly emphasized. In sharp contrast to claims in the discourse advocating geoengineering [4], the discourse critical of geoengineering maintains that geoengineering is highly speculative since several options cannot be tested at large scale. According to this storyline, global geoengineering is untested and will remain so because it is inherently untestable. There is simply no way to identify the harmful side-effects in advance, because geoengineering technologies cannot be tested in laboratories, but must be deployed at full scale to conduct meaningful evaluations. Moreover, it is impossible to calculate the long-term consequences in a system as complex as the global ecosystem. No matter how great the research efforts, claims about the outcomes of geoengineering will still be speculative. Accordingly, "geoscientific speculation" would be a more appropriate name for geoengineering research, which is an activity that cannot be regarded as scientific [32, 46,47,48,49,50,51,52,53]. 
Another argument for refraining from geoengineering research is that its use will create a trap. Richard Turco [31] and Clive Hamilton [54] argue that the use of technologies that stop global warming through blocking sun radiation from reaching the earth's surface will make it necessary to continue using this kind of technology forever. Since the levels of greenhouse gases will keep rising and the earth's temperature will be regulated by artificial shielding, any breakdown or failure to maintain the operation of the technology will lead to rapid climate collapse. In this storyline, it is "crazy" to install a technological system that will have to be maintained for centuries in order to avoid global catastrophe. Making the survival of the planet dependent on forever maintaining sulphur injections or $\mathrm{CO}_{2}$ removal, for example, would be a severe and regrettable mistake. It is unreasonable to count on such continuity in civilization and to preclude any possibility of reversing the climate change process should the unforeseeable side-effects turn out to be devastating. From this perspective, geoengineering would be like walking deeper into a labyrinth with no exit $[31,37,47,48,52,53,54,55,56]$.

Given the risk of discontinuity, this critical storyline (i.e., the technological gamble with the planet) holds that it is immoral to depict geoengineering as a quick technological fix. If the technology can ever be operationalized, doing so will be neither quick nor easy, it will certainly not be cheap, and it will probably not fix things either. The claim that it will be easier to solve the climate crisis with the help of geoengineering schemes that promise to "fix the planet" than to decrease $\mathrm{CO}_{2}$ emissions via political negotiations is deemed utterly simplistic and morally irresponsible $[31,32,45,46,47,48,57,58]$.

Since 2009, several environmental organizations, such as the Canadian NGO ETC Group and Friends of the Earth, began to object to general geoengineering plans and to specific geoengineering projects. A German-Indian project to conduct iron fertilization in part of the Southern Ocean generated protests in early 2009, and the British SPICE project to test sulphur injection into the atmosphere triggered even more opposition by environmental groups in 2011 [36,42,59,60,61,62,63,64]. By voicing their objections to the testing, these groups made the storyline of geoengineering as a dangerous technology with unforeseeable and possibly catastrophic environmental side-effects more widespread and influential. They argued that field testing should not be allowed and that there should be a moratorium on geoengineering, at least until its risks were better understood. The ETC Group even sent an open letter to the UK government asking it to stop planned field tests. Their letter referred to the 2008 UN Convention on Biological Diversity that included a moratorium on ocean fertilization. Two years later, the 193 countries that signed the Convention expanded the moratorium's scope to encompass all geoengineering technologies. The storyline of geoengineering as dangerous technologies with unforeseeable and potentially catastrophic side-effects obtained strong institutional support and the critics obtained a formal document that they could cite in their efforts to oppose general proposals to increase geoengineering research and deployment [33,51,59,60,62, $65,66,67,68,69,70,71,72]$. Several geoengineering proponents declared that there was no need to worry that geoengineering research would stop, since the USA had not ratified the Convention [66, $73,74,75,76]$. However, since that time, newspaper articles have reported considerable opposition to geoengineering and that the resistance groups and their arguments have gained influence $[28,36,42,57,58,59,61,62,65,77,78,79]$. As journalist Eli Kintisch demonstrates in his book Hack the Planet [80], this was not the case before 2009, when geoengineering advocates were unchallenged in media reports. Pat Mooney, executive director of the ETC Group, declared that some geoengineering advocates found it "easier to manage the sun than to get people to take a bus". Henceforth, geoengineering was heavily opposed and even ridiculed [81,82], which had not been the case previously.

\subsection{The inability to handle structural dysfunction}

A second storyline treats geoengineering as the ultimate sign of contemporary industrial society's inability or unwillingness to confront its endogenous and fundamental structural dysfunctionality. Geoengineering is depicted as ecological modernization at its most extreme or, in the words of Canadian author Naomi Klein, as "the ultimate expression of a desire to avoid doing the hard work of reducing emissions" [83]. The attractiveness of geoengineering among scientists, politicians, and business organizations is then understood as related to the possibility of maintaining current systems of transportation, energy consumption, and industrial production. According to this storyline, some 
geoengineering advocates believe that societal shifts towards a low-carbon economy can be avoided if geoengineering is deployed. Geoengineering proponents are understood as defending the belief that it is unnecessary to revise the goals of economic growth and to stop increasing consumption, since deploying the new technologies implies that rising $\mathrm{CO}_{2}$ concentrations will not cause global warming or will be counteracted. The explicit suspicion permeating this storyline is that, if geoengineering proves successful, the governments of rich countries will prefer geoengineering at the expense of $\mathrm{CO}_{2}$ mitigation. The causes of climate change will be left untouched, business will go on as usual, and the fundamental structural problems of unsustainable ecological footprints will be passed on to future generations $[22,31,49,51,54,62,65,76,84,85,86,87,88,89]$. As Clive Hamilton puts it:

If our failure to cut emissions is due to the power of corporate interests, growth fetishism and the comfortable conservatism of consumer society, then resorting to geoengineering acts to deflect attention, to avoid facing up to social dysfunction. [22]

This storyline depicts geoengineering as a set of technologies that addresses only the symptoms of climate change and completely disregards its causes. In this manner, geoengineering is held to be dangerously short-sighted, representing a deceptively easy way out. Accordingly, geoengineering is understood as a dead end, or as methods that might move us several steps farther along a catastrophic path. These new technologies are said to provide an excuse for not making the necessary changes in lifestyles and consumption patterns in the rich countries. People in these countries are thereby provided with a reason for not accepting slow or zero growth, shrinking their ecological footprints, transitioning to renewables, downscaling, and so on, at the same time as the political decision-makers are relieved of the burden of imposing considerable reductions in global $\mathrm{CO}_{2}$ emissions. According to this storyline, geoengineering unfortunately works to sustain the unsustainable and aggravates an already disastrous global predicament $[31,47,49,54,65,70,79,84,86,89,90,91,92,93]$. Pat Mooney (ETC Group), states that geoengineering is "a political strategy aimed at letting industrialized countries off the hook for their climate debt" [65 cf. 54]. In the same spirit, Naomi Klein has declared:

The appeal of geoengineering is that it doesn't threaten our worldview. It leaves us in a dominant position. It says that there is an escape hatch. So all the stories that got us to this point, that flatter ourselves for our power, will just be scaled up. [83]

And Vandana Shiva has added:

Climate change is really the pollution of the engineering paradigm, when fossil fuels drove industrialism. To now offer that same mindset as a solution is to not take seriously what Einstein said: that you can't solve the problems by using the same mindset that caused them. So, the idea of engineering is an idea of mastery. [47]

This storyline emphasizes that there is no need for geoengineering: existing technologies and renewables would surely be sufficient to considerably decrease $\mathrm{CO}_{2}$ emissions if they were deployed worldwide $[94,95,96,97,98,99]$. However, this would require radical systemic change, which the governments of the world are unwilling or unable to accept. This is where geoengineering presents itself as a pseudo solution, maintaining the status quo or, in the long run, possibly even worsening the global climate crisis $[47,49,51,76,80,87,89]$.

Clive Hamilton maintains a critical stance and claims that a "distinctively American world view" is guiding the appeals for geoengineering research and deployment, and that European countries such as Germany are, unlike the UK, much more circumspect about the actual technologies $[43,49,88,100]$. This interpretation is supported by media reporting of an ocean fertilization project in spring 2013 . The US and UK media reported that the experiment indicated that the technology had some potential, while German newspaper headlines consistently declared that the results indicated that ocean fertilization was "keine Lösung" (i.e., no solution) [97,98,101,102,103,104,105,106]. 


\subsection{The geoclique and the Trojan horse}

This storyline describes geoengineering as a business proposal in environmentally friendly guise, as an extreme and grand-scale form of industrial "greenwashing". The main actors are a "geoclique" of very active scientists, experts, and journalists heavily promoting intensified research and investment in research projects in order to develop various geoengineering technologies. The group is regarded as informally led by scientists such as Ken Caldeira and David Keith [80]. For example, Clive Hamilton maintains that the global geoengineering debate has been completely dominated by a few North American scientists conducting geoengineering research who frame the actual technologies as a prerequisite for planetary survival [43]. According to the storyline, the geoclique has established itself as an obligatory passage point in geoengineering discourse, and has been successful in building alliances with powerful actors in order to support their research, and also attract funds, especially from private funders such as Bill Gates and private trusts. The geoclique has also advocated public funding of geoengineering research, since it claims that geoengineering is the only option left to prevent the horrors of climate change in a situation in which international political negotiations have failed to reach agreement on global decreases of $\mathrm{CO}_{2}$ emissions [34,43,51,54,73,107]. According to the ETC Group, the geoclique concentrates on discussing and advocating research into geoengineering instead of the deployment of these technologies, as if it were possible to separate the two activities. From the ETC Group's perspective, this is misleading and maybe even deliberately manipulative, since experience has shown that grand-scale deployment is necessary to enable evaluation of the consequences of these technologies, even in a very restricted sense [51].

The critical environmental NGOs (ENGOs) compare the geoclique's strategy to Odysseus' invention of the Trojan horse. For example, the British small-scale research project SPICE, intended to investigate the possibility of injecting sulphur into the atmosphere through a hose, was understood as recalling Odysseus' lethal military strategy. An important aspect of the analogy is the illusion that the Trojan horse was a beautiful and harmless gift from the gods, which enticed the Trojans to pull it inside the walls of Troy. Once the horse was brought within the walls there was no turning back for the Trojans, and at night, Odysseus' men stole out of the hollow figure, slew the guards, and opened the doors for the Greek army, which killed almost all the city's inhabitants. Similarly, the ETC Group and a few other critical voices have maintained that seemingly harmless, innocent, and possibly even beautiful research projects, once implemented, would "open the door for full-scale deployment of the technology" with catastrophic consequences $[70,108,109]$.

Accordingly, allowing research into geoengineering was expected to be a lethal mistake, no matter how harmless and fascinating it might superficially seem. According to the storyline, intense lobbying is supporting the geoclique and trying to admit the "Trojan horse". Venture capitalists and conservative think tanks together with the military form a powerful lobby for geoengineering $[22,34,43,50,54,73,85,86,107,110,111]$. Spokespersons for the ETC group and Greenpeace have added that the fossil fuel industry is using geoengineering as an excuse for not cutting $\mathrm{CO}_{2}$ emissions and that the industry supports geoengineering research and deployment in order to continue with business as usual. They claim that the fossil fuel industry would surely benefit if the atmosphere could be manipulated to resist increasing levels of $\mathrm{CO}_{2}$ emissions, and that this economic interest induces the industry to support geoengineering research both economically and politically by lobbying, in a democratically contestable way $[34,51,111]$.

Jim Thomas, research programme manager at the ETC Group, was extremely critical, comparing the hubris permeating geoengineering plans with deepwater oil exploration in the Gulf of Mexico. According to Thomas, the Deepwater Horizon environmental disaster did not prevent BP from continuing with their exploitation of hard-to-reach oil or from lobbying for geoengineering schemes with completely unknown and potentially devastating environmental consequences, since both could prove profitable [68]. Greenpeace spokesperson Doug Parr shared this conviction, declaring that geoengineering had become an alternative because governments were unable to resist fossil fuel industry lobbying to avoid decreases in $\mathrm{CO}_{2}$ emissions when a quick technological fix might be at hand [111]. In line with this, some of the biggest geoengineering "cheerleaders" are said to be conservatives and conservative think tanks, such as the Bipartisan Policy Center and the Copenhagen 
Consensus Center led by Bjørn Lomborg, which were formerly sceptical of climate change or even denied its existence and now argue that cooling the planet through geoengineering will be a swift and efficient way to counteract global warming if necessary. According to this storyline, the step from climate scepticism to advocating geoengineering research and deployment is a small and usual one in conservative think tanks, all in order to protect the interests of US fossil-fuel-dependent industries, the energy and transport industries, and the American way of life $[43,51,54,73,86,107,110]$. As the ETC Group notes in Geopiracy, their report on geoengineering:

For those who previously doubted (or still do) the science of anthropogenic global warming, the geoengineering approach shifts the discussion from reducing emissions to an end-of-pipe solution. [51, p. 15]

Another strong criticism of the geoclique and its supporters is that several of the most prominent scientists promoting geoengineering have personal economic interests related to patent rights in the development of geoengineering technologies. Researchers who were members of the UK Royal Society's working group on geoengineering held patents on geoengineering processes while the group of which they were members was recommending more research. According to the storyline, this made it impossible to judge whether the scientists advocating specific geoengineering methods on scientific grounds were arguing for the benefit of the global climate or because of private profit motives. A severe conflict of interest permeated the arguments favouring huge investments in geoengineering research as well as proposals for specific field experiments $[43,54,107,111]$. This was also highlighted in 2011 when the British field experiment SPICE was cancelled, according to the project leaders because of problems with intellectual property, regulations, and public engagement [112,113; cf. 65]. The journalist John Vidal at The Guardian summarized the situation:

In sum, this coalition of US expertise is a group of people which smell vast potential future profits for their institutions and companies in geoengineering. Watch out. This could be the start of the next climate wars. [107]

Depicting a considerable proportion of geoengineering advocates as having hidden agendas, working for narrow interests, or having highly personal motives obviously serves to discredit the arguments for geoengineering. This storyline deconstructs the advocates' self-declared stance of being truly concerned about the global environment and more or less compelled to be frontrunners in seeking radical climate change solutions [34,47,51,85,107,110]. This storyline goes hand in hand with advocacy of deliberation and public engagement, which is the heart of the final storyline.

\subsection{The democratic deficit and the need for public engagement}

The fourth storyline emphasizes that geoengineering is primarily a moral and political concern, and not an issue to be left to scientists and engineers, as is assumed in the dominant advocacy discourse.

Since the consequences of geoengineering technologies are unforeseeable and potentially harmful, and could reshape life worldwide, there are moral and political questions related to both its research and deployment. This understanding is reinforced by the assumption that the technologies, once deployed, will affect several coming generations and be extremely difficult to refrain from. According to the storyline, it is difficult to find technologies that involve deeper and farther-reaching moral decisions, an aspect to which geoengineering advocates pay insufficient attention. This storyline depicts scientific knowledge as strictly limited with regard to decisions of geoengineering deployment and claims that, when it comes to really important questions concerning moral and political judgments, no one can claim expertise. No matter how strong the scientific and technological arguments favouring geoengineering, questions concerning how the technologies will affect countries around the world, the global ecosystem, and future generations in the long term are the important ones, and they are beyond the scope of geoengineering research. In sum, the really important questions concerning geoengineering and its incredible risks are neglected or forgotten in the public debate; this calls for the rapid and fundamental democratization of the issue, for which various environmental organizations and social scientists are increasingly striving [34,62,65,69,107,114; cf. 115]. Vandana Shiva made the following statement: 
But the second most important part of why geoengineering is so wrong is that it is the ultimate expression of patriarchal irresponsibility. Patriarchy is based on appropriating rights and leaving responsibility to others. In this case the scientists who are playing these games, the investors financing it, are all doing it without having any consent for these experiments, any approval for these experiments, locally or globally, and worse, without thinking of the consequences or what it can lead to, and without ever being bound to responsibility. Therefore it is the ultimate expression of all the destructive tendencies of patriarchy. [47]

The argument in this storyline is consistent with Loukannen et al.'s [13] observation that those opposing geoengineering mainly use metaphors that either question or set aside the technology's functioning and instead focus on ethical or governance-related concerns. Furthermore, a related problem, according to the storyline, is an equally alarming lack of formal international rules and institutions governing geoengineering deployment. For geoengineering even to be considered calls for international regulations governing all efforts to technologically alter the climate. The absence of international rules and negotiations concerning the testing and deployment of geoengineering creates a dangerous situation in which individual countries could deploy technologies with unforeseeable global consequences without the agreement of the countries that would suffer the severest side-effects. According to the storyline, this regulatory vacuum is unacceptable and there is an absolute need for an international agreement. This raises the question of how such a geoengineering agreement could be reached, in light of the present difficulties reaching international consensus on clean energy and energy efficiency, and whether it really would be easier to envision the governance of unproven geoengineering technologies than of already available conventional options $[26,32,37,40,51,71,116]$. Vandana Shiva expresses this criticism as follows:

What geoengineering is doing is saying 'let's put our foot on the accelerator'. And the precipice is climate instability and climate unpredictability. And the root of it is the false idea that these silly little actions will be able to control and regulate the weather and the climate. [47]

According to the storyline, the international governance of geoengineering may, because of the scale and uncertainty of the side-effects, be as complicated as any efforts to reduce international $\mathrm{CO}_{2}$ emissions or make lifestyle changes. Geoengineering also creates new governance problems; according to James Fleming, "It could be attempted unilaterally, or worse, proliferate among rogue states, and it could be militarized"[32]. This leads to the conclusion that geoengineering is an illusory quasi-solution and that the only responsible alternative is to concentrate on addressing the cause of global warming. The ETC Group and several other actors articulating the storyline ask "Who has the right to set the global thermostat?" [32,51]. The scandalous answer, they claim, is that no geoengineering proponents know, have the slightest idea, or have even bothered to seriously consider the question [51,62,68]. According to the storyline, geoengineering will be a new kind of neocolonialism or, in the words of the ETC Group, "an act of piracy" as long as this question remains unanswered. In this vein, geoengineering is understood as a technological fix to enable the governments of the rich world to avoid confronting the worldwide ecological consequences of structural societal dysfunctionality and unsustainable growth fetishism. Instead of changing systems for energy supply, transportation, and production, the countries of the rich world seem prepared to take the enormous risk of altering global climate through geoengineering; it is the global South that will suffer the most severe and devastating side-effects, at the same time as this part of the world will be least capable of managing them $[26,32,46,47,51,60,62,67,68,70,116]$.

The storyline contains claims that this problem calls for public involvement in a thorough social and political debate concerning geoengineering. Incorporating the views of the general public is deemed absolutely necessary to enable legitimate political decisions when the risks are enormous and the uncertainty great. What is considered an acceptable global risk can never be anything but a political question concerning all the peoples of the world. Critical ENGOs found it "bizarre" that the British scientists of the 2011 SPICE project had discussed the matter with only a few members of the public before starting the research. Sixty global environmental groups demanded that it must be cancelled, and some opponents even turned to the UK government with a request to block the project since the 
test date was announced before sufficient public debate about its potential consequences had been possible [34,51,65,69,72,107; cf. 115]. In line with this, there is a claim in the storyline that public resistance to geoengineering is increasing, and that "fierce debate" will rage as soon as geoengineering becomes a concrete option. The public silence that has so far greeted geoengineering is already beginning to give way [cf. 11], it is claimed, and deployment will lead to explosive controversies worldwide concerning ecological mega-risks, fair global distribution of the climate debt, and responsibility for future generations and other species $[61,62,68,69,117]$.

\section{Discussion}

\subsection{The advocacy discourse and the common understandings of geoengineering}

The advocacy discourse, which dominated mass media reporting before the critical discourse emerged, initially anticipated the problems of geoengineering and presented the risks openly [4]. We claim that this early openness and reflexivity concerning the problems of geoengineering are unusual when it comes to large-scale technologies. Critical ENGOs and other critical actors have only added a few new technical arguments to the debate or highlighted new risks that the advocates have not already investigated or at least have claimed to be aware of [cf. 118]. In the forthcoming debate, these new risks were also openly acknowledged and treated as relevant problems in the advocacy discourse [4]

The problem of maintaining long-term continuity in geoengineering management is one of several critical concerns acknowledged in both discourses. The problem was recognized in the advocacy discourse and has been investigated, or at least debated, for some years (i.e., [11,14]). A common position in the discourse critical of geoengineering is that geoengineering, and, in particular, sufficient knowledge of its full-scale consequences, is constrained by inherent knowledge gaps unless the technologies are implemented at large scale. The notion that several particular geoengineering options, such as SAI, are fundamentally untestable unless applied at large scale can also easily be found in the advocacy discourse; the conclusion diverges from that of the discourse critical of geoengineering, because the former discourse holds that improved modelling and simulations can at least improve the robustness of current knowledge and provide a clearer view of the future $[2,4]$. According to the critical discourse, there is a remarkable lack of moral discussion when it comes to geoengineering, at the same time as the dominant discourse presents the technologies as a way to prevent the horrors of climate change. Anshelm and Hansson [4] and Scholte et al. [11] demonstrate that the pro-geoengineering discourse actually touches on issues of morality and democracy and has done so since 2006, although these are not the most emphasized issues. The advocacy discourse does not necessarily regard it as a prerequisite that these issues be resolved before research starts; rather, some issues will simply have to be dealt with as they arise.

The geoengineering controversy differs considerably from other techno-political conflicts over grandscale energy-related technologies, for example, concerning nuclear power, hydropower, or carbon capture and storage, which also included controversies concerning strictly technical problems that were often initially identified by the critics. Stirling [10] emphasises that a central belief in the modernity was that innovations, and in particular grand scale energy technology, uncritically were recognised as progress. During the development of, for example, the nuclear industry in the 1970s, which according to Stirling [10] is the most canonical example of modernity, oppositional scientists, and later other concerned groups, attempted to deconstruct the nuclear advocates' scientific truth claims and visions of a better or even utopian future on purely technical and scientific grounds. In this process, significant problems or alternative technical improvements of the criticized technology were initially identified by the critics and, after a period of controversy, were eventually internalized by nuclear power advocates as well. The critics gained legitimacy by being proactive in narrow technical discussions and, ironically, as the technology they criticized improved thanks to this dialogue, they also strengthened the advocates' trustworthiness $[119,120]$.

The advocacy discourse's prior admission of problems and risks in geoengineering rhetorically challenges the discourse critical of geoengineering: the main objections and problems have already been anticipated by the discourse advocating geoengineering, which has not even left space to 
criticize the promise that geoengineering will guarantee a better future. The expectations concerning geoengineering articulated in the advocacy discourse can even be negative: implementation may not succeed and, even if it does, it will not enable increased economic growth, long-term sustainable development, or other positive side-effects; it may even cause worse damage than doing nothing at all. The environmental consequences, or side-effects, were spelled out as potentially severely harmful. The development enthusiasm and high expectations permeating modern technologies seem to be absent and have instead been replaced with self-reflexivity [4].

Another example of this self-reflexivity is that the advocacy discourse also agrees that geoengineering treats only the symptoms of climate change and has a conservative effect on current unsustainable societal and industrial structures. However, one important dissimilarity is that, unlike the discourse critical of geoengineering, it does not regard interference with these structures as doable or, in some cases, as even desirable. This conservative stance is not denied in the advocacy discourse, though it does not explicitly claim that the technology is for the better; instead, it emphasizes that geoengineering buys time in which to develop truly sustainable solutions in the long term irrespective of whether these are radical societal change, renewables, or perfected geoengineering. There is no choice but to adhere to contemporary industrial capitalism, even though the only alternative (geoengineering) cannot guarantee a sustainable future. Geoengineering has to be tested or implemented, no matter what the consequences [cf. 25]. We have previously called this stance industrial cynical fatalism [4]. Accordingly, it is not primarily the understanding of the technical characteristics and feasibility of geoengineering, or even the perceived environmental side-effects, that differs between the discourses, but rather the view of the urgency and feasibility of fundamental change in the socioeconomic structures of contemporary industrial societies. Following Mark Fischers' [121] argumentation concerning the most prevalent state of mind in "late capitalist society", this is not necessarily a matter of cynicism or apathy, but of what he calls reflexive impotence. The advocacy discourse depicts the situation as bad but, more importantly, also acknowledges that no one can do anything about it except advocate technologies or solutions that can be accommodated by the capitalist system - there is no alternative to the market and capitalism, even though other systems might be preferable. For the advocate, this "realism" turns any notion of hope into a perilous illusion, a stance that gives rise to important demarcation lines between the two discourses.

\subsection{Comparing the discourses}

In the advocacy discourse, geoengineering proponents are described, by both themselves and the mass media, as reluctantly favouring research and deployment, well aware of and seriously considering all the technology's risks [4; cf. 5]. There is an unusual degree of self-reflexivity in the progeoengineering discourse [see also 24]. Most of the risks and dangers that the discourse critical of geoengineering has been stressing since 2009 had been put on the agenda and thoroughly discussed in the advocacy discourse several years before. Taking this into consideration, one might initially expect the common understanding of the mega-risks related to geoengineering and a seemingly shared view of the climate crisis to be a good basis for a mutual understanding of geoengineering, but this is not the case. On the contrary, the conclusions regarding the future of geoengineering are opposed between the two discourses. In the following, we will tentatively explain the contrasting conclusions concerning geoengineering put forward in the two discourses.

The mega-risks related to geoengineering technologies are generally acknowledged by all participants in the public debate and are obviously not the main reason why the discourse critical of geoengineering is slowly gaining ground, even though this discourse strongly emphasizes the dangers of technologically gambling with nature. Our analysis demonstrates that the critical discourse differs from and questions the dominant pro-geoengineering discourse regarding six, partly overlapping central points that might help explain its raison d'être.

First, the discourse critical of geoengineering maintains that the proposed field experiments will never provide the answers needed in order to evaluate the future side-effects of full-scale deployment. Taking the complexity of the global ecosystem and environmental history into consideration makes it obvious that not even global geoengineering deployment could obtain the required answers in time. Accordingly, geoengineering can never be a matter of scientific investigation but of sheer belief or 
speculation. Advocating and putting trust in geoengineering research is simply a waste of valuable time and a way of making people and politicians believe that there is a scientifically proven way out of the climate dilemma. The Promethean and Soterian worldviews, as presented by Hamilton [25], may illustrate many of the diverging views in this respect - it is a matter of contrasting worldviews and man-nature relationships. According to Hamilton, the Promethean worldview is confident in both humanity's ability to control nature and in the appropriateness of doing so, while the Soterian worldview considers these grand mastery projects as symptoms of hubris. The Prometheans claim that humanity has already (successfully) engineered its environment, making the step to engineering the entire planet both smaller and more natural. In contrast, as already hinted, the Soterians consider those aspirations, given humanity's history of creating environmental disasters and its inability to control and predict nature, as bound to fail - especially because geoengineering would add complexity to the world system. This is exactly what for example Vandana Shiva and Naomi Klein as well as the ETC Group points to.

Second, the popular understanding of geoengineering as a method for buying time in order to make way for renewables and a low-carbon society is completely discounted in the critical discourse. The transition to a low-carbon society must not be delayed any longer. The climate crisis is already here and considerable $\mathrm{CO}_{2}$ emission reductions must be made immediately. Developing and evaluating geoengineering will waste valuable time: this will not mean buying time, but rather spending or losing it. This is why the countries of the world cannot afford geoengineering. The discourse critical of geoengineering claims that geoengineering opportunities could result in the avoidance of $\mathrm{CO}_{2}$ emission reductions and delay the necessary mitigation of climate change. Geoengineering is a way of postponing the unavoidable structural change of contemporary society.

Third, the most horrifying risks of geoengineering are, according to the discourse critical of geoengineering, not directly related to its deployment, but to its reinforcement of unsustainable social and economic structures. Geoengineering is just another step along a catastrophic path, and it is based on the same rationality and the same project of conquering nature that laid the groundwork for the present global predicament. Conquering technologies such as geoengineering are part of the problem, not of the solution. The urgent need for a fundamental reform of industrial society and a break with socially dysfunctional and environmentally devastating striving for economic growth is stressed. It has become necessary to rapidly reduce the ecological footprint of industrialized society and, unfortunately, geoengineering is heading in exactly the opposite direction. The opportunity to technologically manipulate the atmosphere, allowing emissions to continue unaltered, is frightening: it holds out the prospect of business as usual, a prospect that would be irresistibly tempting to industrial companies, politicians, and large segments of the populations of the rich countries.

Fourth, in much of the discourse critical of geoengineering, geoengineering is depicted as an act of piracy, a form of neo-colonialism. If deployed, it will preserve unjust international social, economic, and environmental relationships. The environmental consequences of deployment will also be unevenly distributed. Poor countries will have to suffer from the environmentally most severe sideeffects, while the rich countries will possess the economic and scientific ability to research and deploy geoengineering. Accordingly, power over the global side-effects of these technologies will be in the hands of a few wealthy nations. Since international regulations governing geoengineering are currently weak, these nations will effectively be "controlling the global thermostat". This entails a severe risk that the atmosphere of the global south will become the next object for the ongoing process of colonization. Geoengineering will free the rich countries from their historical climate debt, while simultaneously creating a new one.

Fifth, the critical discourse is profoundly suspicious that several of the leading proponents of geoengineering are not primarily devoted to long-term sustainability worldwide, but rather to promoting their own profits (e.g., from patent rights), advancing personal careers, or serving the interests of think tanks or the fossil fuel industry. These accusations have been levelled because some researchers have been found to have both scientific and economic interests in specific technologies or field experiments, and because some of their work has been financed by venture capitalists. The 
strong support that geoengineering efforts have received from conservative think tanks and fossil fuel industry lobbying has certainly strengthened these suspicions.

Sixth, the discourse critical of geoengineering insists that international political action is both possible and necessary. While the discourse advocating geoengineering presupposes that the political process has proven itself unable to reduce $\mathrm{CO}_{2}$ emissions, the critical discourse states that political solutions, based on grassroots movements and NGOs as well as UN declarations, are the only possible ways to counteract climate change. Leaving the future of the planet in the hands of big science, big business, and big politics, all stuck in the paradigm of ongoing economic growth, would be an utterly dangerous and regrettable mistake.

In sum, the fundamental dissensus between the two discourses is related mainly to how the views of social change, knowledge limits, and humanity's ability to control nature are spelled out in the two discourses. While the critical discourse stresses the possibility and necessity of fundamentally changing existing social, economic, and political structures, the advocacy discourse downplays these questions and instead emphasizes that new technologies must be developed immediately to counteract climate change. The idea that it might be possible to save the planet by deploying grand-scale technology is depicted in the discourse critical of geoengineering as both a Promethean dream and a way of sustaining the unsustainable, i.e., a way to maintain dysfunctional societal structures. On the other hand, the visions of a fundamentally reoriented society that permeate the critical discourse are deemed naïve and possibly even irresponsible in the advocacy discourse in this age of global environmental threats.

Moreover, the until recently nearly hegemonic dominance of the advocacy discourse has not encouraged the fundamental questioning of geoengineering or created room for political controversies. However, as geoengineering research or even deployment is carried out, and as the public debate becomes more intense, this situation will probably change dramatically. The result might well be that the techno-political conflict over geoengineering will come to resemble the conflicts concerning other grand-scale technologies to an extent not yet seen.

\section{Acknowledgments}

Many thanks to the participants in the seminar group 'Green Critical Forum' at Linköping University. Thanks also to two anonymous reviewers for insightful comments. We also acknowledge funding from the Swedish Research Council Formas and The Swedish Research Council (Vetenskapsrådet).

\section{References}

1. Shepherd J, Caldeira K, Haigh J, Keith DW, Launder B, Mace G, MacKerron G, Pyle J, Rayner S, Redgwell C. Geoengineering the climate - science, governance and uncertainty. London: The Royal Society; 2009.

2. Lawrence MG, Crutzen PJ. The Evolution of Climate Engineering Research. Geoengineering Our Climate. Working Paper and Opinion Article Series; 2013.

3. Crutzen PJ, Albedo Enhancement by Stratospheric Sulfur Injections: A Contribution to Resolve a Policy Dilemma? Climatic Change 2006;221:220-77.

4. Anshelm, J, Hansson A, The last chance to save the climate? An analysis of geoengineering's advocates discourse in the public debate. Forthcoming in Environmental Humanities.

5. Buck HJ. What can geoengineering do for us? Public Participation and the new media landscape. Available at: 
http://umt.edu/ethics/ethicsgeoengineering/Workshop/articles1/Holly\%20Buck.pdf; 2010. (Accessed 2014-03-07)

6. Why geoengineering suits Russia's carbon agenda. The Guardian, 2013-09-24

7. IPCC. Summary for Policymakers. In: Metz B. Davidson OR, Bosch PR, Dave R, Meyer LA, editors. Climate Change Mitigation. Contribution of Working Group III to the Fourth Assessment Report of the Intergovernmental Panel on Climate Change, Cambridge, Cambridge: University Press; 2007.

8. World won't cool without geoengineering, warns report. New Scientist, 2013-09-25

9. Sovacool, BK. What are we doing here? Analyzing fifteen years of energy scholarship and proposing a social science research agenda. Energy Research \& Social Science 2014 (in press)

10. Transforming power: Social science and the politics of energy choices. Energy Research \& Social Science 2014 (in press)

11. Scholte S, Vasileiadou E, Petersen AC. Opening up the societal debate on climate engineering: How newspaper frames are changing. J of Int Env Sci 2013;1:16-10.

12. Buck HJ. Climate engineering: Spectacle, tragedy or solution? A content analysis of news media framing. In: Methmann C, Rothe D, Stephen B, editors. (De-)Constructing the Greenhouse: Interpretative Approaches to Global Climate Governance, Abingdon: Routledge; 2013.

13. Loukkanen M, Huttunen S, Hildén M. Geoengineering, newsmedia and metaphors: Framing the controversial. Public Underst of Sci doi:10.1177/0963662513475966;2013.

14. Nehrlich B, Jaspal R. Metaphors we die by? Geoengineering, metaphors and the argument from catastrophe. Metaphor and Symbol 2012;131:147-27.

15. Porter KE, Hulme M. The emergence of the geoengineering debate in the UK print media: a frame analysis. The Geographical J 2013;342:355-4.

16. Sikka T. A critical discourse analysis of geoengineering advocacy. Critical Discourse Studies 2012;163:175-9.

17. Cairns R. Examining framings of geoengineering using Q methodology. Climate Geoengineering Governance Working Paper Series: 002, Oxford; 2013.

18. Fairclough N. Analysing Discourse Textual Analysis for Social Research, London: Routledge;2003.

19. Heitmann Hansen O, Langhelle O, Anderson R. Framework and Methodology: Regulation and Discourse analysis as a research strategy. In: Mikkelsen A, Langhelle O, editors. Arctic Oil and Gas: Sustainability at Risk? New York: Routledge; 2008, pp. 15-45.

20. Lovell H, Bulkeley H, Owens S. Converging agendas: Energy and climate change in the UK. Env and Planning C: Government and Policy 2008;90:109-27.

21. Hajer M. The politics of environmental discourse: ecological modernization and the policy process. Oxford: Clarendon; 1995.

22. Hamilton C. The new sorcerer's Apprentices. Earth Island Journal; 2013.

23. Coffey A, Atkinson P. Making sense of qualitative data: Complementary Research Strategies. Thousands Oaks: SAGE; 1996.

24. Linnér B-O, Wibeck V. Climate engineering as emerging technologies: A review of the literature. Unpublished results.

25. C. Hamilton (2013) Earthmasters: The Dawn of the Age of Climate Engineering. Yale University Press; 2013.

26. Climate engineering: Cheap solutions not necessarily the best. The Jakarta Post 2009-10-01

27. Künstliche Wolken gegen die Erderwärmung. Die Welt 2009-12-03

28. Geo-Engineering: Bizarre Ideen zum Kampf gegen die Erderwärmung. Die Welt 2009-12-03 
29. Bizarre Ideen zum Kampf gegen die Erderwärmung. Die Welt 2009-12-03

30. Künstliche $\mathrm{CO}_{2}$-Reduktion: Neuer "Geo-engineering"-Ansatz mit globalen Nebenwirkungen. Der Standard 2010-02-21

31. Richard Turco on the Nuttiness of Climate Engineering. Silobreaker 2010-06-30

32. Weather as a Weapon. Slate Magazine 2010-09-24

33. Geoengineering: global warming antidote? USA TODAY 2011-02-25

34. The link between BP, geoengineering and GM. The Ecologist 2011-05-14

35. What can we do to save our planet? The Independent 2009-01-02

36. Das Meer wird zum Bioreaktor. Spiegel Online 2009-01-27

37. Regeln für Klimaklempner fehlen. Tagesspiegel 2010-09-27

38. Eine Studie befasst sich mit Großtechnik gegen Klimawandel. Tagblatt online 2011-10-14

39. What the UN ban on geoengineering really means, New Scientist, November, 2010.

40. Geoengineering To Mitigate Global Warming May Cause Other Environmental Harm. Science Daily 2009-08-06

41. What can we do to save our planet? The Independent 2009-01-02

42. Klimawandel: Geoengineering kann ein Plan B in der Klimapolitik sein. Die Zeit 2011-11-29

43. The clique that is trying to frame the global geoengineering debate. Guardian Professional Networks 2011-12-05

44. Luftige forslag som har null prosent sjanse for å virke. Nettavisen 2009-12-14

45. Goodell J. How to cool the planet - geoengineering and the audacious quest to fix earth's climate. Boston/New York; Houghton Mifflin Harcourt; 2010.

46. Can space reflectors save us? Why we shouldn't buy into geoengineering fantasies. Slate, 2009-09-23

47. TERRA FUTURA 2013: Interview with Vandana Shiva about geoengineering. NoGeoingegneria 2013-07-09

48. Ocean Geoengineering Scheme No Easy Fix For Global Warming. Terra Daily 2010-02-23

49. Geoengineering: Our last hope, or a false promise? Tehran Times 2013-05-27

50. Geoengineering: The War on Climate Change We Don't Need. Common Dreams 2013-05-28

51. ETC-group. Geopiracy: The case against geoengineering. ETC Group Communique no. 103; 2010.

52. No Quick Or Easy Technological Fix For Climate Change Researchers Say. Science Daily 2008-12-19

53. Climate Engineering Is Doable, as Long as We Never Stop. Wired News 2007-07-25

54. An evil atmosphere is forming around geoengineering. Silobreaker 2010-07-14

55. Geo-engineering: just a sticking plaster for the planet? The Guardian 2009-10-21

56. Carbon dioxide levels hit record high. Noodls 2013-05-13

57. We can't fix the planet: There is no easy solution for climate change. It's a symptom of our man-made world. Slate, 2009-09-24

58. Sweet dreams are made of geoengineering. Reuters 2009-09-03

59. U.N. Says 'No,' Climate Hackers Say, 'Yes We Can'. Reuters 2009-03-05

60. As climate talks drag on, more ponder techno-fixes. Fox News 2010-12-04

61. Scientists to deploy giant balloon $20 \mathrm{~km}$ above earth in climatecooling. Business Green 201109-01

62. A Stadium-Sized Balloon In The Stratosphere Could (Re)Engineer The Climate Fast Company 2011-09-10

63. 'Climate Fix' ships sets sail with plan to dump iron. New Scientist 2009-01-09

64. Hacking the Planet: The only climate solution left? New Scientist 2009-02-25 
65. CLIMATE CHANGE: Geoengineering for a Desperate Planet. Inter Press Service 2010-1026

66. Fair Weather Foes: UN Bans Geoengineering Research. Fast Company 2010-11-01

67. SPICE put on ice. Nature News Blog 2011-09-30

68. Giant balloon to test climate fix. BBC 2011-09-14

69. Would-be geoengineers must listen to the public. New Scientist 2011-10-03

70. US geoengineers to spray sun-reflecting chemicals from balloon. Guardian 2012-07-17

71. Biodiversity Meeting Calls for More Science-Based Information. Individual.com 2012-10-24

72. Scientists criticise handling of pilot project to 'geoengineering' climate. The Guardian 2011$11-17$

73. A Ban on Geoengineering Research: Bad Idea. Time 2010-11-03

74. Give geo- and genetic engineering a fair trial. New Scientist 2011-09-07

75. Geoengineering: Why We Need to Test It, and Soon. Time 2011-09-07

76. Australia to broach radical global warming solutions. The Sydney Morning Herald 2011-0909

77. Can geoengineering put the freeze on global warming? USA TODAY 2011-02-25

78. To Fight Warming, Brits Plan to Launch a Huge Balloon and Really Long Pipe. Popular Science 2011-09-01

79. Rules Lacking for Geoengineering Projects for Global Warming. LiveScience.com 2012-0807

80. Kintisch E. Hack the planet - Science's best hope or worst nightmare for averting climate catastrophe. New Jersey: John Wiley \& Sons; 2010.

81. CLIMATE CHANGE: Geoengineering for a Desperate Planet. Tierramerica Environment and Development 2010-10-25

82. Colbert Nation. Available at: http://www.colbertnation.com/the-colbert-reportvideos/431083/december-09-2013/david-keith 2013-12-09. (Accessed 2014-03-07)

83. Green groups may be more damaging than climate change deniers. Earth Island Journal 201309-05

84. Why geoengineering has immediate appeal to China. Guardian 2013-03-22

85. The Fallacy of Geo-Engineering. RINF.com 2013-05-24

86. Climate: action, impact, and geoengineering. Resilience 2013-05-24

87. Annalee Newitz's outlook on extinction is positively optimistic. The Globe and Mail 201305-25

88. Geoengineering: an earthly gamble to combat global warming. Sacramento News \&amp; Review 2013-06-06

89. Don't let the skeptics win. Philippine Daily Inquirer 2013-06-06

90. Climate change: Can we even do it? Should we even try? CNN 2009-10-29

91. Geo-engineering: a bad idea whose time has come? London South East 2011-12-09

92. The Climate Change Endgame. The New York Times 2013-01-21

93. Green warriors turn to engineering to save the Earth. New Indian Express 2013-06-09

94. Ingeniører: Vi kan nå klimamål. TV 2 Fyn 2009-09-03

95. Ingeniører efterlyser elbiler og effektivisering. Business.dk 2009-09-03

96. SA wants technology diffusion to developing countries at centre of Copenhagen deal Engineering. News 2009-09-04

97. Engineering 'better than tax on climate'. Scientific American 2009-09-04

98. En tredje industrirevolution efterlyses. Ingenjören 2009-09-04

99. Befintlig teknik knäcker klimathotet. Ny teknik 2009-12-09 
100. Absage ans Geo-Engineering: Regierung lehnt Klima-Operationen ab. Spiegel Online 2012-07-17

101. Forscher: Geoengineering bei Ozeanen löst $\mathrm{CO}_{2}$-Problem nicht Rhein. Main Presse 2013-01-22

102. Mineral dust sprinkled in oceans could absorb vast amounts of carbon: study. Guardian 2013-01-22

103. Klimawandel: Geoengineering löst $\mathrm{CO}_{2}$-problem nicht. Handelsblatt 2013-01-22

104. Olivin: Ozeane profitieren von Chemie-Staubsauger zu wenig. Die Welt 2013-01-23

105. Ozeandüngung untauglich gegen Klimawandel. Die Welt 2013-01-23

106. Researchers analyse 'rock dissolving' method of geoengineering. Space Daily 2013-0124

107. Big names behind US push for geoengineering. Guardian Professional Networks 2011$10-06$

108. Die Welt ist gefangen in der Klimafalle. Neue Zürcher Zeitung 2011-10-17

109. Grüne Technologien: Warnung vor den Klima-Klempnern. Die Tageszeitung 2011-1006

110. [112] Rachel Smolker: Geoengineering Is a Dangerous Solution to Climate Change. Huffington Post Canada 2013-03-22

111. Man-made eruptions: Plan B in the battle for the planet. The Independent 2009-09-02

112. Canceled: 'Artificial Volcano' Test for Geoengineering. Climate Scientific American 2012-05-16

113. Climate fix test grounded again. BBC 2012-05-16

114. Handle With Care. The New York Times 2008-08-12

115. Engineering a climate solution. New York Times 2009-09-01

116. Investment in geo-engineering needed immediately, says Royal Society. The Guardian 2009-09-01

117. Public Awareness of Geoengineering Science Increasing. Science Magazine 2011-1024

118. Robock A. 20 reasons why geoengineering may be a bad idea. 2008;14-18-64.

119. Anshelm J, Galis V. (Re-)constructing nuclear Waste Management in Sweden: The Involvement of Concerned Groups. In: Kumar S editor. Integrated Waste management. In Tech, Rijeka; 2011, p. 401-430.

120. Hansson A, Bryngelsson M. Expert opinions on carbon dioxide capture and storage: A framing of uncertainties and possibilities. Energy Policy 2009;2273-2282-37.

121. Fischer M. Capitalist realism: Is there no alternative? Ropley: O Books, Ropley; 2009. 